\title{
Cost-effectiveness of apixaban and warfarin in the prevention of thromboembolic complications among atrial fibrillation patients
}

\author{
Taru Hallinen ${ }^{1 *}$, Erkki J. Soini ${ }^{1}$, Miika Linna ${ }^{2}$ and Samuli I. Saarni ${ }^{3}$
}

\begin{abstract}
Background: To reduce the risk of thromboembolic complications, clinical guidelines recommend anticoagulation treatment for almost all atrial fibrillation (AF) patients. Although warfarin has long been the primary treatment alternative, now newer alternatives such as apixaban have proven effective in prevention of the thromboembolic complications of non-valvular AF. The aim of this study is to assess the cost-effectiveness of apixaban when compared with warfarin in the prevention of AF-associated thromboembolic complications in Finland.

Methods: The assessment was performed with a lifetime Markov-model with the following health states: non-valvu$\operatorname{lar} \mathrm{AF}$, ischemic stroke, hemorrhagic stroke, other intracranial bleed, other major bleed, clinically relevant non-major bleed, myocardial infarction, and systemic embolism. The treatment efficacies were obtained from the ARISTOTLE trial. Representative Finnish input data were used for the model states, including background mortality, resource use, costs (in 2014 values), and EQ-5D-3L-based quality of life. The results (with $3 \%$ annual discounting) are presented as incremental cost-effectiveness ratios [ICER, cost per quality-adjusted life year (QALY) gained], the expected value of perfect information (EVPI), and the probability of apixaban being cost-effective at various willingness-to-pay levels.

Results: Apixaban increased life-expectancy by 0.17 years and quality-adjusted life-expectancy by 0.14 QALYs when compared with warfarin. Additional QALY was gained with apixaban at a cost of 1824 euros based on the deterministic analysis. The maximum EVPI was 649 euros/patient at 1282 euros per QALY gained in the probabilistic analysis. The probability of apixaban being cost-effective reached $80 \%$ when the willingness-to-pay per QALY gained was 14,857 euros. In deterministic sensitivity analyses, ICERs varied from dominance of apixaban to additional QALY being gained at a cost of 12,312 euros.
\end{abstract}

Conclusions: The ICERs obtained were well below the WHO-CHOICE threshold values for cost-effective interventions, suggesting that apixaban is a very cost-effective treatment alternative for warfarin in Finnish patients with AF.

Keywords: Anticoagulation, Apixaban, Atrial fibrillation, Cost-utility, Stroke, Warfarin

\section{Background}

Atrial fibrillation (AF) is a major risk factor for stroke, increasing the risk of stroke approximately fivefold (Wolf et al. 1991). In Finland, approximately $13 \%$ of all patients with ischemic stroke have a prior diagnosis of AF (Meretoja et al. 2011). Warfarin has long been the recommended

\footnotetext{
${ }^{*}$ Correspondence: taru.hallinen@esior.fi

${ }^{1}$ ESiOR Oy, Tulliportinkatu 2 LT4, 70100 Kuopio, Finland

Full list of author information is available at the end of the article
}

antithrombotic treatment for AF patients as it reduces the risk of stroke by approximately $60 \%$ (Hart et al. 2007). However, characteristics of warfarin including frequent monitoring of international normalized ratio (INR) and numerous drug interactions limit its use. Recent Finnish studies suggest that warfarin is underused among $\mathrm{AF}$ patients. Approximately $50 \%$ of all AF patients for whom anticoagulation is recommended in the Finnish Current Care Guideline (2015) based on their stroke risk (i.e. 
$\mathrm{CHA}_{2} \mathrm{DS}_{2}$-VASc $\geq 1$, see e.g. Lip et al. 2010) were treated with warfarin in one municipality (Hallinen et al. 2014) and $30 \%$ of the previously diagnosed AF patients admitted to Finnish emergency departments due to AF did not receive warfarin treatment at the time of hospitalization despite their moderate to high risk of stroke (Lehto et al. 2011).

New anticoagulant treatments such as apixaban, dabigatran, and rivaroxaban have all proven effective in the prevention of thromboembolic complications in patients with non-valvular AF (Granger et al. 2011; Connolly et al. 2009; Patel et al. 2011). In Finland and many other countries the decision on whether to publicly fund the use of these drugs is at least partially based on the cost-effectiveness of the drug against the most-used treatment. In Finland, the costs of these new anticoagulants are currently reimbursed (35\% of costs are covered by the Social Insurance Institution) for patients with high risk of embolism (i.e. $\mathrm{CHA}_{2} \mathrm{DS}_{2}$ VASc $\geq 2$ ) and patients with moderate risk of embolism (i.e. $\mathrm{CHA}_{2} \mathrm{DS}_{2}$-VASc $=1$ ) when warfarin cannot be used due to its side-effects or interactions or when patients' INRvalues during stabilized warfarin treatment remain in the target range less than $70 \%$ of the time (Kela 2015).

The aim of this study was to assess the cost-effectiveness of apixaban when compared with warfarin in the prevention of thromboembolic complications in Finnish AF patients. The study applies previously unpublished health care costs and quality of life estimates that have been observed for Finnish patients in real-life setting.

\section{Results}

Apixaban use increased life-expectancy and quality adjusted life-expectancy on average by 0.17 and 0.14 years, respectively, when compared with warfarin (see Table 1). These gains were reached at an additional cost of 261 euros during patient's life-time. An additional quality-adjusted life year (QALY) was therefore gained at a cost of 1824 euros, which is clearly below the commonly used threshold values for incremental cost-effectiveness ratios (ICERs) that are considered to support claims of cost-effectiveness. The cost-effectiveness plane illustrating differences in costs and effects between apixaban and warfarin is shown in Fig. 1.

The cost-effectiveness acceptability frontier (CEAF) in Fig. 2 shows the probability of the optimal treatment being the most cost-effective treatment alternative at various willingness to pay (WTP) thresholds per QALY gained. The probability of apixaban being cost-effective reached $80 \%$ when the WTP per QALY gained was 14,857 euros. Apixaban had 91 and $94 \%$ probability for cost-effectiveness when the WTP was 37,576 and 112,728 euros per QALY gained, respectively. Based on the probabilistic simulation results and Bayesian treatment ranking, apixaban had $95 \%$ probability of being the first best option in terms of highest QALYs and had $45 \%$ probability for the lowest costs.

As can be seen from Fig. 2, expected value of perfect information (EVPI) reached its maximum value of 649 (2.5-97.5\% percentile 0-3409) euros per patient when the probabilistic ICER was 1282 euros per QALY gained. The EVPI was 166 (0-2556) and 234 (0-3474) euros per patient when WTP was 37,576 and 112,728 euros per QALY gained, respectively.

In deterministic sensitivity analyses ICERs varied between negative values, i.e. apixaban dominated warfarin, and 12,312 euros per QALY gained. The highest ICERs were obtained in scenarios where apixaban was

Table 1 Results of the cost-effectiveness analyses

\begin{tabular}{|c|c|c|c|c|c|c|c|}
\hline & \multicolumn{3}{|c|}{ Lifetime costs $(€)$} & \multicolumn{3}{|c|}{ Lifetime QALYs } & \multirow[t]{2}{*}{ ICER (€/QALY gained) } \\
\hline & Apixaban & Warfarin & Diff. & Apixaban & Warfarin & Diff. & \\
\hline Base case & 16,197 & 15,936 & 261 & 7.19 & 7.05 & 0.14 & 1824 \\
\hline Without discounting & 20,647 & 20,442 & 205 & 8.99 & 8.80 & 0.19 & 1060 \\
\hline \multicolumn{8}{|l|}{ Sensitivity analyses } \\
\hline CHADS 0-1 & 15,491 & 14,931 & 560 & 7.25 & 7.12 & 0.13 & 4347 \\
\hline CHADS 2 & 16,151 & 15,708 & 443 & 7.20 & 7.07 & 0.13 & 3387 \\
\hline CHADS 3-6 & 17,012 & 17,266 & -254 & 7.13 & 6.96 & 0.17 & Dominant \\
\hline TTR $<52.38 \%$ & 16,047 & 17,150 & -1104 & 7.19 & 6.97 & 0.22 & Dominant \\
\hline $52.38 \% \leq \mathrm{TTR}<66.02 \%$ & 17,397 & 16,170 & 1226 & 7.14 & 7.04 & 0.10 & 12,312 \\
\hline $66.02 \% \leq \mathrm{TTR}<76.51 \%$ & 16,164 & 15,131 & 1033 & 7.20 & 7.10 & 0.10 & 10,386 \\
\hline $\mathrm{TTR} \geq 76.51 \%$ & 15,150 & 15,249 & -98.23 & 7.25 & 7.10 & 0.15 & Dominant \\
\hline No treatment discontinuations after trial period & 19,473 & 19,042 & 431 & 7.24 & 7.04 & 0.21 & 2102 \\
\hline Warfarin monitoring cost $-50 \%$ & 16,197 & 14,650 & 1546 & 7.19 & 7.05 & 0.15 & 10,817 \\
\hline Warfarin monitoring cost $+50 \%$ & 16,197 & 17,222 & -1025 & 7.19 & 7.05 & 0.14 & Dominant \\
\hline
\end{tabular}




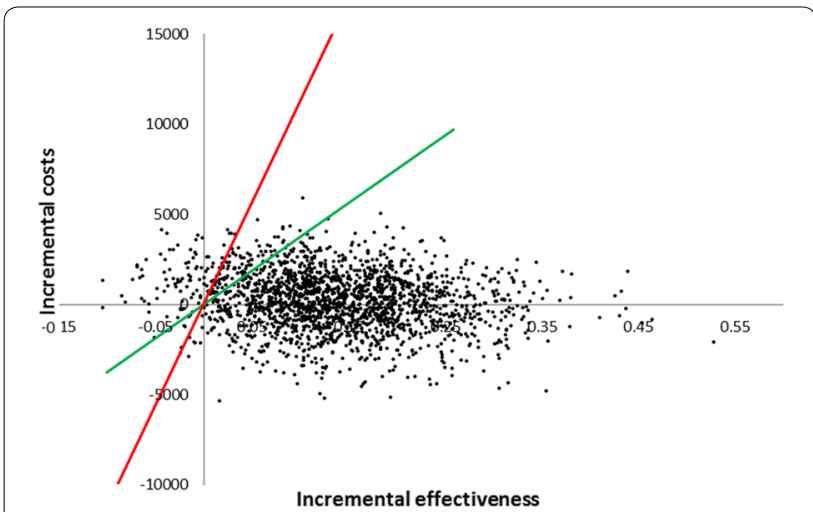

Fig. 1 The cost-effectiveness plane for apixaban versus warfarin. Green line depicts ICER threshold equal to the Finnish GDP and red line depicts ICER threshold equal to 3 times the Finnish GDP

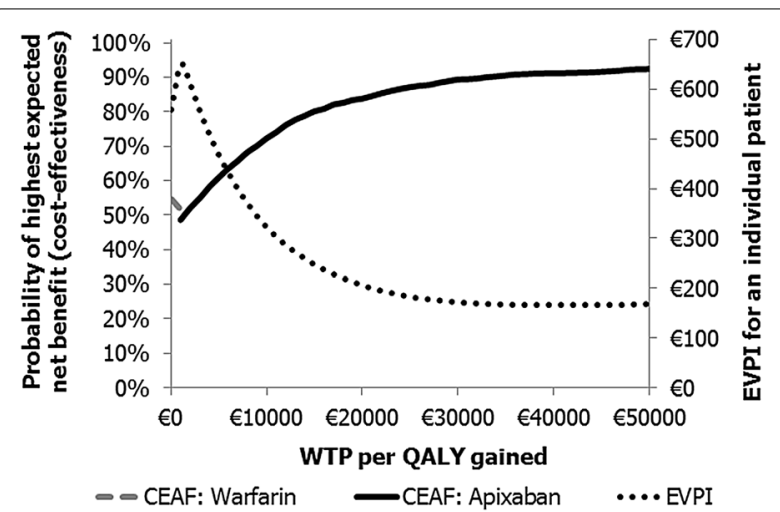

Fig. 2 Cost-effectiveness acceptability frontier (CEAF) and expected value of information (EVPI) curves for the analysis. WTP=willingness to pay

compared with warfarin treatment with intermediate percentage times spent in the therapeutic INR range (TTRs) and when the cost of monitoring for warfarin was reduced by $50 \%$. Even the highest ICERs obtained were well below the common official international and unofficial Finnish cost-effectiveness thresholds of 30,000 and 47,000 euros per QALY gained.

\section{Discussion}

Apixaban use increased average treatment costs, lifeexpectancy, and quality-adjusted life-expectancy of AF patients when compared with warfarin. An additional QALY was gained with apixaban at a cost of 1824 euros. Based on WHO-CHOICE threshold values for cost-effectiveness (WHO 2016), our analysis suggests that apixaban can be considered a very cost-effective treatment alternative to warfarin in Finland. Based on a recent systematic literature review of cost-effectiveness studies of the new oral anticoagulants, our finding is in line with published assessments from other countries (Kansal et al. 2013).
Based on the extensive sensitivity analyses and CEAF, the results obtained were relatively robust and the probability of apixaban being cost-effective was high. The expected value of obtaining additional information for uncertain probabilistic model parameters remained relatively low and was around 649 euros per patient at maximum. This finding suggests that further research to reduce the uncertainty would be worthwhile only if the costs associated with further research were less than 649 euros per study participant.

Perhaps the most interesting practical finding of our study was the non-linearity of ICERs with regard to warfarin treatment quality. ICERs were lowest when the TTR was at either the higher or lower end of the spectrum. The highest ICERs were observed for intermediate TTRs. Although the subgroups analyses of the ARISTOTLE trial were not powered to detect significant differences between warfarin and apixaban in these TTR subgroups, it seems possible that in centers with high TTR values the patients may have been at higher risk of bleeds when compared with centers with lower TTRs. Because apixaban use is associated with a lower risk of bleeds when compared with warfarin, this observation could explain the improvement in the cost-effectiveness of apixaban as TTR with warfarin increases. Interestingly, a recent Finnish study (Soini et al. 2013) observed a potential association between higher TTR and lower quality of life (QoL), perhaps reflecting a similar phenomenon.

On a broader perspective our assessment shows that QALYs gained during anticoagulation treatment are associated with reasonable costs in relation to benefits gained regardless of whether the patients are treated with apixaban or warfarin. In fact, our analysis illustrates a rare case (see Soini et al. 2012) in which the ICER between compared treatments is very similar to the average costeffectiveness ratios (CER, i.e. cost/QALY for each comparator) for apixaban (2253 euros) and warfarin (2260 euros). Based on the Bayesian treatment ranking of lowest CER, the probability of being the first best option was $53 \%$ for apixaban and $47 \%$ for warfarin. Even though the CERs implicitly reflect a comparison setting in which the comparator to given treatment would be "instant death" without any costs or QALYs (Soini et al. 2012), very high CERs may indicate that the treatment would not be considered acceptable from cost perspective (an exception to this interpretation would be the case in which the choice to "do nothing" or sc. "instant death" would lead to higher CER). In our study, this is clearly not an issue for either treatment. In the absence of common comparator, relative benefit of apixaban and warfarin versus the common comparator (e.g. placebo) could not be estimated and, thus, relative benefit-CER (see Soini et al. 2016) or ICERs in terms of given treatment versus the common 
comparator were not implemented in this study. In fact, because warfarin was the recommended treatment practice at the time of ARISTOTLE trial, a placebo-controlled trial would have been unethical.

Our study has some important strengths. We collected both the cost and QoL data from representative Finnish data sources, thereby increasing the validity of our results in the Finnish context. Furthermore, the patient characteristics and risk factors in the ARISTOTLE trial have previously been found to be similar to those of Finnish patients with atrial fibrillation (Hallinen et al. 2014). Our study also broadens the available information regarding the impact of stroke severity on patients' QoL and costs. To our knowledge, such data or results have not been published previously. Lastly, we presented the probabilistic results in terms of CEAF and EVPI.

There are always some limitations in cost-effectiveness assessments of chronic long-term illnesses that are based on modeling. AF is an especially complex disorder that has an impact on many health-related outcomes. Some aspects of the model used for this assessment can be considered conservative. An example of such an assumption is the modeling of most events as absorbing states. This assumption means that after experiencing an event the patients were no longer at risk of other costly events. Such an assumption tends to favor the treatment that has proven less effective.

There is also some uncertainty regarding the potential QoL loss and costs associated with warfarin monitoring. A recent Finnish study suggests that warfarin monitoring may result in some QoL loss (Soini et al. 2013), which was not accounted for in our analysis. Another recent study (Hallinen et al. 2014) shows that the Finnish national unit costs (Hujanen et al. 2008) used in this study for warfarin monitoring may not be generalizable across Finland and in fact may underestimate the true payer costs, at least for some municipalities. Since we excluded the possible QoL loss associated with warfarin, estimated warfarin treatment costs based on national unit costs, excluded potential benefits from the re-allocation of warfarin monitoring resources (i.e. the opportunity cost of labor needed in warfarin monitoring may be higher than its unit cost) for other purposes (Hallinen et al. 2012a, b), and the results were observed to be sensitive to warfarin treatment costs, our cost-effectiveness estimates may be conservative, at least for some municipalities.

\section{Conclusions}

The ICERs obtained for apixaban were well below the WHO-CHOICE thresholds for cost-effective interventions, indicating that apixaban is a very cost-effective treatment alternative for warfarin in Finnish patients with AF. Based on the sensitivity, cost-effectiveness acceptability frontier, and expected value of perfect information analyses, the results were relatively robust; apixaban had a high probability of cost-effectiveness and the value of additional information for the probabilistic model parameters was relatively low.

\section{Methods}

The cost-effectiveness assessment was performed using a life-time Markov health state transition model with 6-week cycles that extrapolate the trial findings to a longer term. Since the model structure has been previously described in detail by Dorian et al. (2014), it is summarized only briefly here. The assessment was based on the efficacy and safety findings from the ARISTOTLE trial (Granger et al. 2011) together with Finnish data for QoL, costs, and mortality. ARISTOTLE trial was a multicentre, randomized, double-blind trial, comparing apixaban (5 $\mathrm{mg}$ twice daily) with warfarin (target international normalized ratio, 2.0-3.0) in 18,201 patients with atrial fibrillation and at least one additional risk factor for stroke. Direct comparisons from randomized, double-blind trials are the favored data source for assessing health effects of compared treatments in Finland (Pharmaceuticals Pricing Board 2015), and ARISTOTLE trial is the only published phase III trial comparing aprixaban and warfarin in AF. We used secondary analysis of ARISTOTLE to derive model inputs (Dorian et al. 2014).

The main outcome measure was ICER calculated as the quotient of the mean cost and effectiveness differences between apixaban and warfarin. Since there are no official Finnish thresholds for cost-effectiveness (Soini et al. 2015) available, we applied the WHO-CHOICE thresholds in the assessment (WHO 2016). Accordingly, the intervention is considered very cost-effective, cost-effective or not cost-effective, when the ICER is below the gross domestic product (GDP) per capita $(<37,576$ euros/ QALY gained based on the Finnish GDP in 2014 according to Official Statistics of Finland 2016), the ICER is 1-3 times the GDP per capita (37,576-112,728 euros/QALY gained) or the ICER is higher than three times the GDP per capita ( $>112,728$ euros/QALY gained), respectively. The WHO-CHOICE thresholds are surprisingly similar to the overall results of the eight patient groups in a Finnish contingent valuation study, where also average WTP of 47,000 euros per QALY gained was observed for coronary heart disease (Soini et al. 2012). The effectiveness was estimated on the basis of QALY. QALYs were based on the survival and QoL was measured using EQ-5D-3L. All costs and outcomes were discounted at an annual rate of $3 \%$.

A probabilistic sensitivity analysis (PSA) with 2000 simulations was performed. In the PSA, the values of 
key input parameters were varied based on their probability distributions. A cost-effectiveness plane based on the PSA was drawn to illustrate the observed differences in costs and effects between compared treatments. In addition, a CEAF was drawn to depict the probability of cost-effectiveness for optimal treatments (in terms of net monetary benefit obtained) at different values of WTP per QALY gained (Barton et al. 2008; Soini et al. 2011). Conditional Bayesian Treatment Ranking (BTR) has been recently proposed as an assessment method for treatment ranking in terms of the probabilities for the first highest, second highest etc. benefits and the first lowest, second lowest etc. ICER versus minimum treatment (Soini et al. 2016). We used the BTR to define the probabilities for the first highest QALYs, lowest costs and lowest average cost-effectiveness ratios (CER). In addition, the EVPI was estimated to assess the value of obtaining more information (Barton et al. 2008) on probabilistic model parameters in order to reduce the uncertainty associated with the treatment decision. A high EVPI suggests that there is a need for additional information (i.e. the net monetary benefit gains from new research information may exceed the research costs) or that the opportunity cost should be considered in decision-making (Soini et al. 2011).

\section{Model}

A schematic presentation of the model used is presented in Fig. 3. The modeled cohort consists of male (64.7\%) and female $(35.3 \%)$ patients with non-valvular AF, aged 70 years, and with an average $\mathrm{CHADS}_{2}$-score (see Gage et al. 2001) of 2.1 (Dorian et al. 2014), which is well in line with the Finnish values (see Hallinen et al. 2014). In the model the patients start anticoagulation treatment and are modeled to reside in the "atrial fibrillation" health state until they die or experience one of the following

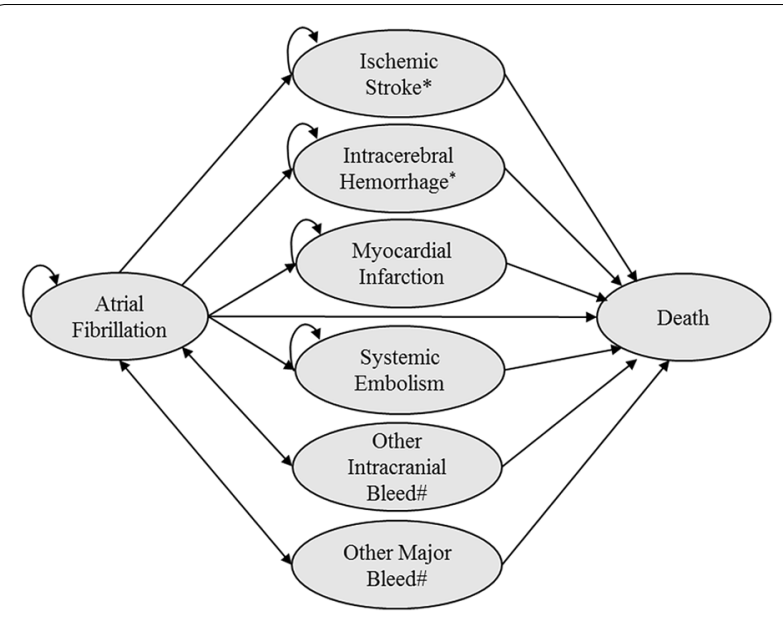

Fig. 3 Schematic presentation of the cost-effectiveness model permanent health events: ischemic stroke (mild, moderate, severe or fatal), hemorrhagic stroke (mild, moderate, severe or fatal), systemic embolism, or myocardial infarction (MI); or one of the following transient mutually exclusive events: other intracranial bleed (ICB), other major bleeds (gastrointestinal bleeds or other bleeds), or clinically relevant non-major bleeds. After permanent events the patients are no longer at risk of other events apart from death. After transient events the patients recover their previous health states after one cycle. The event rates are summarized in Table 2.

Mortality is modeled separately for the above health events (Dorian et al. 2014) and other causes. The other cause mortality is modeled on the basis of official Finnish life tables by applying a weighted relative risk of 1.24 for death due to AF as compared with the general Finnish population. The applied increase in mortality risk was based on the finding that AF increases the mortality risk by approximately 1.5 -fold in women and 1.1-fold in men (Benjamin et al. 1998). Similarly, mortality is increased after stroke (both ischemic and hemorrhagic) and MI when compared with the general population. We derived the following standardized mortality ratios from the studies by Huybrechts et al. (2008) and BrønnumHansen et al. (2001): mild stroke 1.386, moderate stroke 2.440, severe stroke 6.384, MI women 2.330, and MI men 1.740. In addition, Finnish case fatality rates were applied for event rates that were not available from the ARISTOTLE trial. The case fatality rate for systemic embolism $(10.5 \%)$ was approximated from the Official Statistics of Finland $(2010,2011)$ and the case fatality rate for MIs was estimated from the Finnish National Cardiovascular Diseases Register based on year 2012 (14.2\% for men and $16.9 \%$ for women). The Finnish 30 day-case fatality for MI among patients who make it to the hospital has been reported to be $13.5 \%$ for men and $15.8 \%$ for women (Häkkinen et al. 2007), but these rates exclude patients who die before being hospitalized.

In the model, the patients may discontinue their anticoagulation treatment due to modeled events or unrelated reasons after which they may switch to a second-line treatment [warfarin, acetylsalicylic acid (ASA)] or to no treatment. For simplicity we assumed that the patients would not receive further antithrombotic treatment after treatment discontinuance. Permanent treatment discontinuance was assumed for all hemorrhagic strokes whereas patients with other ICBs and other major bleeds were assumed to discontinue treatment either permanently or temporarily for 6 weeks as described by Dorian et al. (2014).

The model allows the adjustment of stroke and bleeding risks during warfarin treatment based on the TTR. The event rates for patients with different TTRs were 
Table 2 Risk of modeled health events according to treatment

\begin{tabular}{|c|c|c|c|c|}
\hline & \multicolumn{2}{|c|}{$\begin{array}{l}\text { ARISTOTLE } \\
\text { Rate per } 100 \text { patient years }{ }^{1}\end{array}$} & \multicolumn{2}{|c|}{$\begin{array}{l}\text { Second line treatment } \\
\text { Rate per } 100 \text { patient years }\end{array}$} \\
\hline & Apixaban & Warfarin & ASA $^{c}$ & No antithrombotic treatment \\
\hline \multicolumn{5}{|l|}{ Ischemic stroke by $\mathrm{CHADS}_{2}$-score } \\
\hline 0-1 (34 \% of patients) & 0.521 & 0.458 & & \\
\hline 2 (35.8 \% of patients) & 0.950 & 0.934 & & \\
\hline $3-6$ (30.2 \% of patients) & 1.534 & 1.944 & & \\
\hline Weighted average/average & 0.981 & 1.021 & 2.280 & $2.81^{2}$ \\
\hline Hemorrhagic stroke & 0.254 & 0.512 & 0.388 & - \\
\hline Other intracranial bleed & 0.076 & 0.288 & 1.455 & - \\
\hline Other major bleed: gastrointestinal & 0.680 & 0.795 & 1.455 & - \\
\hline Other major bleed: not gastrointestinal & 1.110 & 1.476 & 1.455 & - \\
\hline Clinically relevant non-major bleed & 2.083 & 2.995 & 1.811 & - \\
\hline Myocardial infarction & 0.530 & 0.610 & 0.616 & $0.856^{3}$ \\
\hline Systemic embolism & 0.090 & 0.100 & 0.600 & $0.486^{4}$ \\
\hline Mortality for the trial duration ${ }^{a}$ & 3.0825 & 3.3404 & & \\
\hline Other cardiovascular hospitalizations & - & - & & \\
\hline Treatment discontinuation $^{b}$ & 13.177 & 14.405 & & \\
\hline \multicolumn{5}{|c|}{ a Other cause mortality after the trial period was estimated by fitting a Gompertz survival function to the Finnish life tables } \\
\hline \multicolumn{5}{|c|}{ b For reasons other than modeled events } \\
\hline \multicolumn{5}{|c|}{ c The relative risk estimates from the AVERROES trial (Connolly et al. 2011) were applied to the apixaban event rates in the ARISTOTLE trial (Granger et al. 2011) } \\
\hline \multicolumn{5}{|c|}{1 Dorian et al. (2014) } \\
\hline \multicolumn{5}{|c|}{2 The ASA event rates were transformed using a relative risk (RR) reduction of 0.19 (Lip and Lim 2007) for ASA versus placebo } \\
\hline \multicolumn{5}{|c|}{3 The ASA event rates were transformed using RR $=0.72$ (Yerman et al. 2007) for ASA versus placebo } \\
\hline 4 An RR of 0.19 for stroke was assumed to ap & well & & & \\
\hline
\end{tabular}

obtained from a secondary analysis of the ARISTOTLE trial data, in which the trial centers were classified into four groups of equal size (i.e. $25 \%$ of the study centers belonged to each group) based on the center's TTR $($ cTTR $<52.38 \%, 52.38 \% \leq$ cTTR $<66.02 \%$, $66.02 \% \leq$ cTTR $<76.51 \%$, and cTTR $\geq 76.51 \%$ ) (Dorian et al. 2014). By varying the proportion of patients belonging to each of these subgroups in the model, the impact of warfarin treatment quality on cost-effectiveness was assessed in a sensitivity analysis.

\section{Quality of life (QoL) estimates}

QoL associated with health states was estimated from a nationally representative sample of Finnish inhabitants who participated in the Health 2000 study (Methodology report, Health 2000 Survey 2008).

In the model, the patients' disability status after stroke is based on the modified Ranking Scale (mRS), which was not assessed in the Health 2000 study as such. Instead, we classified patients into the mRS categories on the basis of their answers to the 'mobility' and 'usual activities' dimensions of the 15D health-related QoL questionnaire (Sintonen 2001) as follows: answers $1-2$ to both $15 \mathrm{D}$ dimensions was considered a mild stroke; answers 3-4 to either dimension was considered a moderate stroke, and answer 5 to either dimension was considered a severe stroke.

The QoL impact of the studied conditions in the Health 2000 study data was estimated using a regression method whereby the differences in utilities measured with EQ5D-3L was explained with the conditions of interest. Due to difficulties in defining appropriate diagnoses for clinically relevant non-major bleeds and other major bleeds in the data set, the impact of these health events was not analyzed in the regression models. The QoL scores associated with health states are reported in Table 3. For probabilistic sensitivity analysis, the QoL values were modeled as beta distributions with large standard errors ( $20 \%$ of the mean value).

\section{Costs}

Health care payer perspective was used in the analysis. Direct health care costs excluding value added tax were included as costs in the analysis. The costs were assessed at real values in 2014 euros.

The applied daily drug cost was 2.77 euros for apixaban (5 mg twice daily) and 0.09 euros for warfarin (5 mg once daily). In addition, 1.67 and $1.80 \%$ of the patients on 
Table 3 Applied average Finnish health state costs (year 2014 values) and quality of life values

\begin{tabular}{|c|c|c|}
\hline Model state & Cost, $€$ & EQ-5D-3L score $(n=5690)$ \\
\hline Atrial fibrillation & & $0.743^{\mathrm{a}}$ \\
\hline Monitoring visit (warfarin only) & $38.39^{b}$ & \\
\hline Routine care, GP visit & $116.82^{c}$ & \\
\hline \multicolumn{3}{|l|}{ Ischemic stroke } \\
\hline Mild & & -0.087 \\
\hline Acute Care, per episode & 4429.23 & \\
\hline $\begin{array}{l}\text { Long-term maintenance, per } \\
\text { month }\end{array}$ & 0 & \\
\hline Moderate & & -0.198 \\
\hline Acute Care, per episode & 7526.19 & \\
\hline $\begin{array}{l}\text { Long-term maintenance, per } \\
\text { month }\end{array}$ & 943.31 & \\
\hline Severe & & -0.644 \\
\hline Acute Care, per episode & 7532.07 & \\
\hline $\begin{array}{l}\text { Long-term maintenance, per } \\
\text { month }\end{array}$ & 4293.22 & \\
\hline Fatal & 5338.33 & \\
\hline \multicolumn{3}{|l|}{ Haemorrhagic stroke } \\
\hline Mild & & -0.071 \\
\hline Acute Care, per episode & 2628.91 & \\
\hline $\begin{array}{l}\text { Long-term maintenance, per } \\
\text { month }\end{array}$ & 2429.02 & \\
\hline Moderate & & -0.352 \\
\hline Acute Care, per episode & 9218.05 & \\
\hline $\begin{array}{l}\text { Long-term maintenance, per } \\
\text { month }\end{array}$ & 2128.67 & \\
\hline Severe & & -0.578 \\
\hline Acute Care, per episode & 9399.58 & \\
\hline $\begin{array}{l}\text { Long-term maintenance, per } \\
\text { month }\end{array}$ & 3722.89 & \\
\hline Fatal & 5564.97 & \\
\hline Systemic embolism & & -0.084 \\
\hline Acute Care, per episode & 2072.39 & \\
\hline $\begin{array}{l}\text { Long-term maintenance, per } \\
\text { month }\end{array}$ & 104.08 & \\
\hline $\begin{array}{l}\text { Other intracranial bleeds, per } \\
\text { episode }\end{array}$ & 4257.04 & $-0.168^{d}$ \\
\hline Other major bleeds & $-0.168^{e}$ & \\
\hline Gl bleeds, per episode & 3448.80 & \\
\hline Non-Gl bleeds, per episode & 3448.80 & \\
\hline Clinically relevant non-major bleeds & 2006.51 & $-0.0582^{f}$ \\
\hline Myocardial infarction & & -0.005 \\
\hline Acute Care, per episode & 5316.31 & \\
\hline $\begin{array}{l}\text { Long-term maintenance, per } \\
\text { month }\end{array}$ & 525.00 & \\
\hline
\end{tabular}

a In the regression model the constant term was 1.068 , the disutility associated with AF was -0.045 , and the decrease in QoL per year of age was -0.004 . As a result, the QoL in AF state equals $0.743(=1.068-0.004 \times 70-0.045$, where 70 is the average age of patients)

b Hallinen et al. (2006, 2012a, b)

c GP-visit at primary health care (Kapiainen et al. 2014)

${ }^{d}$ Disutility applied for 6 weeks

e Assumed to be equal to other intracranial bleeds. Disutility applied for 14 days

f Sullivan et al. (2011). Disutility applied for 2 days apixaban and warfarin, respectively, experienced dyspepsia during treatment in the ARISTOTLE trial. Dyspepsia was assumed to require one general physician (GP) visit, to last for 3 months, and to be treated with pantoprazole $20 \mathrm{mg} /$ day (19.54 euros/package for 3 month treatment). Routine follow-up of patients was assumed to consist of an annual GP visit (116.82€) and warfarin monitoring $(38.39 €)$ was assumed to take place 17 times per year (Hallinen et al. 2006). Similar monitoring frequencies have also been reported in other Finnish studies (Hallinen et al. 2014; Soini et al. 2013).

The cost estimates associated with health states (Table 3) were derived from the Finnish Hospital Discharge Register (see e.g. Sund 2012), which covers the public specialized health care in Finland, and the national hospital benchmarking database (Linna and Häkkinen 2008). First, all patients with a diagnosis of AF (WHO International Classification of Diseases 10 (ICD-10) code: I48, $\mathrm{n}=30,680$ ) were identified from the databases for 2007. Then the costs of care for the acute events, total health care costs for three consecutive years ( 1 year prior and 2 years following the event), and the proportion of patients who died within 1 year of the event were collected. Because the patients' mRS were not available for cost estimation, we classified strokes as mild, moderate, or severe when the patient was discharged home, admitted to a rehabilitative institution or institutional care following the acute event, respectively. Since the health care costs for the first year are typically high due to acute event costs, use of first-year costs would overestimate the costs in successive years. Therefore the annual mortality adjusted maintenance costs (in 2007 values) following the events were estimated as follows: (1) the acute event cost were subtracted from the total costs for 2 years after the event to obtain 2-year maintenance costs; (2) annual maintenance costs were derived from 2-year maintenance costs by assuming that the costs during the first 2 years after events would be equal for patients who are alive at the start of each year [i.e. annual maintenance cost $=2$-year costs $/(1+\%$ of patients alive at the start of year 2)]; (3) the average health care costs for 1 year prior to the index event were deducted from the annual maintenance costs to obtain an estimate of the additional health care costs following the index events. The costs were then inflated into 2014 values with a factor of 1.1998 (Official Statistics of Finland 2015) and into monthly costs by dividing them by 12 .

\section{Sensitivity analyses}

In deterministic sensitivity analyses we tested the impact of the following changes to input variables: (a) varying $\mathrm{CHADS}_{2}$-scores, (b) varying TTR, (c) no treatment 
discontinuations after trial duration, and the cost of warfarin monitoring (d) increased and (e) decreased by $50 \%$.

\section{Abbreviations}

AF: atrial fibrillation; ASA: acetylsalicylic acid; BTR: Bayesian treatment ranking; CEAF: cost-effectiveness acceptability frontier; GP: general physician; ICER: incremental cost-effectiveness ratio; QALY: quality-adjusted life year; EVPI: expected value of perfect information; ICB: intracranial bleed; INR: international normalized ratio; mRS: modified Ranking Scale; MI: myocardial infarction; PSA: probabilistic sensitivity analysis; QoL: quality of life; SE: systemic embolism; TTR: time spent in therapeutic range; WTP: willingness to pay.

\section{Authors' contributions}

TH and EJS designed the study. TH adapted and revised the cost-effectiveness model, carried out the cost-effectiveness analyses, and drafted the first version of the manuscript. EJS carried out the probability of cost-effectiveness, Bayesian treatment ranking and value of information analysis, and helped draft the manuscript. TH, EJS, SIS and ML planned QoL and cost data analyses which SIS and $M L$ carried out, respectively. SIS and ML revised the manuscript for important scientific content. All authors read and approved the final manuscript.

\section{Author details}

${ }^{1}$ ESiOR Oy, Tulliportinkatu 2 LT4, 70100 Kuopio, Finland. ${ }^{2}$ HEMA/Aalto University, TUAS-talo, Otaniementie 17, Espoo, Finland. ${ }^{3}$ Turku University Hospital and University of Turku, P.O. Box 52, 20521 Turku, Finland.

\section{Competing interests}

TH and EJS are employees, board members, and shareholders of ESiOR Oy, which was commissioned by Pfizer Oy (Pfizer) and Oy Bristol-Myers Squibb (Finland) Ab (BMS) to perform this study. EJS is the CEO of ESiOR. Pfizer/BMS are the marketers of apixaban in Finland. Publication fee was paid by ESiOR. ESiOR has carried out commissioned studies and health-economic analysis for several other pharmaceutical companies, food industry companies, device companies, research groups, health care organizations, and hospitals. ML and SIS have received consultancy fees from ESIOR.

\section{Funding}

This study was supported and funded by Pfizer Oy, Helsinki, Finland and Oy Bristol-Myers Squibb (Finland) Ab, Espoo, Finland.

Received: 26 November 2015 Accepted: 9 August 2016

Published online: 17 August 2016

\section{References}

Barton GR, Briggs AH, Fenwick EAL (2008) Optimal cost-effectiveness decisions: the role of the cost-effectiveness acceptability curve (CEAC), the cost-effectiveness acceptability frontier (CEAF), and the expected value of perfection information (EVPI). Value Health 11:886-897

Benjamin EJ, Wolf PA, D'Agostino RB, Silbershatz H, Kannel WB, Levy D (1998) Impact of atrial fibrillation on the risk of death: the Framingham Heart Study. Circulation 98:946-952

Brønnum-Hansen H, Jørgensen T, Davidsen M, Madsen M, Osler M, Gerdes LU, Schroll M (2001) Survival and cause of death after myocardial infarction: the Danish MONICA study. J Clin Epidemiol 54:1244-1250

Connolly SJ, Ezekowitz MD, Yusuf S, Eikelboom J, Oldgren J, Parekh A, Pogue J, Reilly PA, Themeles E, Varrone J, Wang S, Alings M, Xavier D, Zhu J, Diaz R, Lewis BS, Darius H, Diener HC, Joyner CD, Wallentin L (2009) RE-LY Steering Committee and Investigators: dabigatran versus warfarin in patients with atrial fibrillation. N Engl J Med 361:1139-1151

Connolly SJ, Eikelboom J, Joyner C, Diener HC, Hart R, Golitsyn S, Flaker G, Avezum A, Hohnloser SH, Diaz R, Talajic M, Zhu J, Pais P, Budaj A Parkhomenko A, Jansky P, Commerford P, Tan RS, Sim KH, Lewis BS, Van Mieghem W, Lip GY, Kim JH, Lanas-Zanetti F, Gonzalez-Hermosillo A, Dans AL, Munawar M, O'Donnell M, Lawrence J, Lewis G, Afzal R, Yusuf S, AVERROES Steering Committee and Investigators (2011) Apixaban in patients with atrial fibrillation. N Engl J Med 364:806-817
Current Care Guideline, Working group appointed by the Finnish Medical Society Duodecim and the Finnish Cardiac Society (2015) Atrial fibrillation. 24.42015. Helsinki

Dorian P, Kongnakorn T, Phatak H, Rublee D, Kuznik A, Lanitis T, Liu LZ, Iloeje U, Hernandez L, Lip GYH (2014) Cost-effectiveness of apixaban versus current standard of care for stroke prevention in patients with atrial fibrillation. Eur Heart J 35:1897-1906

Gage BF, Waterman AD, Shannon W, Boechler M, Rich MW, Radford MJ (2001) Validation of clinical classification schemes for predicting stroke: results from the National Registry of Atrial Fibrillation. JAMA 285:2864-2870

Granger CB, Alexander JH, McMurray JJ, Lopes RD, Hylek EM, Hanna M, Al-Khalidi HR, Ansell J, Atar D, Avezum A, Bahit MC, Diaz R, Easton JD, Ezekowitz JA, Flaker G, Garcia D, Geraldes M, Gersh BJ, Golitsyn S, Goto S, Hermosillo AG, Hohnloser SH, Horowitz J, Mohan P, Jansky P, Lewis BS, Lopez-Sendon JL, Pais P, Parkhomenko A, Verheugt FW, Zhu J, Wallentin L, ARISTOTLE Committees and Investigators (2011) Apixaban versus warfarin in patients with atrial fibrillation. N Engl J Med 365:981-992

Häkkinen U, Idänpään-Heikkilä U, Keskimäki I, Klaukka T, Peltola M, Rauhala A, Rosenqvist G (2007) PERFECT—Sydäninfarkti. Sydäninfarktin hoito, kustannukset ja vaikuttavuus (PERFECT-myocardial infarction. Treatment, costs and effectiveness). Stakesin työpapereita 15. Valopaino Oy, Helsinki

Hallinen T, Martikainen JA, Soini EJ, Suominen L, Aronkytö T (2006) Direct costs of warfarin treatment among patients with atrial fibrillation in a Finnish health care setting. Curr Med Res Opin 22:683-692

Hallinen T, Soini EJ, Tuovinen M (2012a) Dabigatraanin kustannusvaikuttavuus eteisvärinäpotilaiden aivohalvausten ehkäisyssä (Cost-effectiveness of dabigatran in stroke prevention). DOSIS 28:130-144

Hallinen T, Linnosmaa I, Tuovinen M, Soini E (2012b) Vaihtoehtoiskustannukset ja kustannusvaikuttavuus tuotantoteknologian muuttuessa: esimerkkinä eteisvärinän antikoagulaatiohoito (Opportunity costs and cost-effectiveness in production technology change: case anticoagulation for atrial fibrillation). In: Klavus J (ed) Terveystaloustiede 2012. Yliopistopaino, Tampere

Hallinen T, Soini EJ, Asseburg C, Laakkonen A, Kuosmanen P (2014) Warfarin treatment among Finnish patients with atrial fibrillation: retrospective registry study based on primary health care data. BMJ Open. doi:10.1136/ bmjopen-2013-004071

Hart RG, Pearce LA, Aguilar MI (2007) Meta-analysis: antithrombotic therapy to prevent stroke in patients who have nonvalvular atrial fibrillation. Ann Intern Med 146:857-867

Heistaro S (ed) (2008) Methodology report. Health 2000 survey. Publications of the National Public Health Institute B26. Hakapaino Oy, Helsinki

Hujanen T, Kapiainen S, Tuominen U, Pekurinen M (2008) Terveydenhuollon yksikkökustannukset Suomessa 2006. Stakesin työpapereita 2008:3. Valopaino Oy, Helsinki

Huybrechts KF, Caro JJ, Xenakis JJ, Vemmos KN (2008) The prognostic value of the modified Rankin Scale score for long-term survival after firstever stroke. Results from the Athens Stroke Registry. Cerebrovasc Dis 26:381-387

Kansal AR, Zheng Y, Pokora T, Sorensen SV (2013) Cost-effectiveness of new oral anticoagulants in the prevention of stroke in patients with atrial fibrillation. Best Pract Res Clin Haematol 26:225-237

Kapiainen S, Väisänen A, Haula T (2014) Terveyden- ja sosiaalihuollon yksikkökustannuksen Suomessa vuonna 2011. THL Raportti 3/2014. Juvenes Print, Suomen Yliopistopaino Oy. Tampere

Kela (13.5.2015) Apiksabaani (Eliquis), dabigatraani (Pradaxa) ja rivaroksabaani (Xarelto) 1.6.2015 alkaen - Lääkekorvaustiedotteet - kela.fi. http:// www.kela.fi/laakkeet-ja-laakekorvaukset_laakekorvaustiedotteet/-/ asset_publisher/rUldRaiKF7xv/content/id/2202124

Lehto M, Raatikainen P, Mäkynen H, Peiponen M, Kyhälä-Valtonen $\mathrm{H}$, Hartikainen J, Lund J, Ahonen J, Mäkijärvi M (2011) Eteisvärinän hoito Suomessa -FinFib-tutkimus (Treatment of atrial fibrillation in Finlandthe FinFib study). Suomen Lääkärilehti 66:3401-3407

Linna M, Häkkinen U (2008) Benchmarking Finnish Hospitals. In: Blank J, Valdmanis V (eds) Evaluating hospital policy and performance: contributions from hospital policy and productivity research. Elsevier, Oxford, pp 179-190

Lip GY, Lim HS (2007) Atrial fibrillation and stroke prevention. Lancet Neurol 6:981-993 
Lip GY, Nieuwlaat R, Pisters R, Lane DA, Crijns HJ (2010) Refining clinical risk stratification for predicting stroke and thromboembolism in atrial fibrillation using a novel risk factor-based approach: the euro heart survey on atrial fibrillation. Chest 137:263-272

Meretoja A, Kaste M, Roine RO, Juntunen M, Linna M, Hillbom M, Marttila R, Erilä T, Rissanen A, Sivenius J, Häkkinen U (2011) Direct costs of patients with stroke can be continuously monitored on a national level: performance, effectiveness, and costs of treatment episodes in stroke (PERFECT Stroke) database in Finland. Stroke 42:2007-2012

Official Statistics of Finland (2010) Causes of death (e-publication). Statistics Finland, Helsinki. http://tilastokeskus.fi/til/ksyyt/index.html. Accessed 8 June 2012

Official Statistics of Finland (2011) Somatic specialist medical care 2010. Statistical report 45 , Helsinki

Official Statistics of Finland (2015) Price index of public expenditure (e-publication). Statistics Finland, Helsinki. http://tilastokeskus.fi/til/jmhi/ index_en.html. Accessed 16 Sept 2015

Official Statistics of Finland (2016) National accounts. Statistics Finland, Helsinki. http://www.stat.fi/tup/suoluk/suoluk_kansantalous_en.html. Accessed 14 July 2016

Patel MR, Mahaffey KW, Garg J, Pan G, Singer DE, Hacke W, Breithardt G, Halperin JL, Hankey GJ, Piccini JP, Becker RC, Nessel CC, Paolini JF, Berkowitz SD, Fox KA, Califf RM (2011) ROCKET AF investigators: rivaroxaban versus warfarin in nonvalvular atrial fibrillation. N Engl J Med 365:883-891

Pharmaceuticals Pricing Board (19.8.2015) Preparing a health economic evaluation to be attached to the application for reimbursement status and wholesale price for a medicinal product. Application instructions TTS 19.8.2015. http://www.hila.fi/c/document_library/get_file?folderld=7923 80\&name $=$ DLFE-9119.pdf
Sintonen $\mathrm{H}$ (2001) The 15D instrument of health-related quality of life: properties and applications. Ann Med 33:328-336

Soini E, Martikainen J, Nousiainen T (2011) Treatment of follicular non-Hodgkin lymphoma with or without rituximab: cost-effectiveness and value of information based on 5-year follow-up. Ann Oncol 22:1189-1197

Soini E, Kukkonen J, Myllykangas M, Ryynänen OP (2012) Contingent valuation of eight new treatments what is the clinician's and politician's willingness to pay? Open Complement Med J 4:1-11

Soini E, Koskela T, Ryynänen OP (2013) International normalized ratio (INR) monitoring and percent time in therapeutic INR range (TTR) have impact on patient's quality of life? Application of beta regressions in a prospective 3 months setting. Value Health 16:A535

Soini E, Hallinen T, Sokka AL, Saarinen K (2015) Cost-utility of first-line actinic keratosis treatments in Finland. Adv Ther 32:455-476

Soini E, Hautala A, Poikonen E, Becker U, Kyttälä M, Martikainen J (2016) Costeffectiveness of first line chronic lymphocytic leukemia treatments when full dose fludarabine is unsuitable. Clin Ther 38:889-904

Sullivan P, Slejko J, Sculpher M, Ghushchyan V (2011) Catalogue of EQ-5D scores for the United Kingdom. Med Decis Making 31:800-804

Sund R (2012) Quality of the Finnish Hospital Discharge Register: a systematic review. Scand J Public Health 40:505-515

WHO (2016) WHO|Table: threshold values for intervention cost-effectiveness by region. http://www.who.int/choice/costs/CER_levels/en/

Wolf PA, Abbott RD, Kannel WB (1991) Atrial fibrillation as an independent risk factor for stroke: the Framingham Study. Stroke 22:983-988

Yerman T, Gan WQ, Sin DD (2007) The influence of gender on the effects of aspirin in preventing myocardial infarction. BMC Med 5:29

\section{Submit your manuscript to a SpringerOpen ${ }^{\odot}$ journal and benefit from:}

- Convenient online submission

- Rigorous peer review

- Immediate publication on acceptance

- Open access: articles freely available online

- High visibility within the field

- Retaining the copyright to your article

Submit your next manuscript at springeropen.com 